\title{
Resistive vessel function in coronary artery disease
}

\author{
Neal G Uren, Tom Crake
}

Traditionally, the coronary circulation was divided into two arterial compartments: the conduit and the resistive vessels. It has become apparent that there is substantial heterogeneity in resistive vessels with respect to the regulation of coronary flow, which is modified by the perfusion pressure, flow, myocardial metabolism, and ventricular wall tension. Early in the atherosclerotic process, the ability of the coronary resistive vessels to vasodilate maximally under physiological or pharmacological stress is impaired, ${ }^{1}$ often in the presence of coronary risk factors and before the development of angiographically apparent disease. ${ }^{23}$ There is also some evidence showing that myocardial ischaemia may be caused or exacerbated by an inappropriate vasoconstriction of resistive vessels. ${ }^{45}$

\section{The distribution of the coronary resistance}

The resistive vessels match myocardial blood flow to variable myocardial energy requirements and to myocardial demand when the coronary perfusion pressure varies, such that myocardial oxygen extraction is virtually constant over a wide range of cardiac work and perfusion pressures. Coronary resistance is influenced both by extrinsic factors such as myocardial compression and by intrinsic factors such as tissue metabolism and neural and humoral influences. The influence of myocardial compression means that coronary blood flow ceases when the perfusion pressure is low but still substantially above coronary venous pressure. $^{6}$

Although it was first considered that most resistance to coronary flow resided in arterioles $<100 \mu \mathrm{m}$, much resistance is present in larger arterioles and small arteries up to 300 $\mu \mathrm{m}$ in diameter $(90 \%$ in vessels $<300 \mu \mathrm{m}) .{ }^{7}$ In the cat, $50 \%$ of coronary resistance is in vessels $>100 \mu \mathrm{m}(25 \%$ in vessels $>170 \mu \mathrm{m})$ under basal conditions. ${ }^{8}$ As $10 \%$ of resistance is in the venous compartment, this leaves about $40 \%$ of resistance in the vessels $<100$ $\mu \mathrm{m}$. Pharmacological vasodilatation can alter the distribution of resistance; dipyridamole and adenosine reduce resistance in resistive vessels $<150-170 \mu \mathrm{m},{ }^{9}$ whereas, papaverine preferentially vasodilates larger coronary arterioles and small coronary arteries $(>200 \mu \mathrm{m}){ }^{7}$ Thus coronary resistance coexists in different arteriolar compartments and its distribution may change according to the perfusion pressure and local metabolic environment.

\section{The heterogeneity of the coronary resistive vessels}

Myocardial tissue perfusion is in part modulated by autoregulation - the intrinsic ability to maintain myocardial flow relatively constant after changes in perfusion pressure-and by tissue metabolism. Autoregulation may be influenced by extrinsic factors such as autonomic nervous system activity and circulating hormones, and occurs between perfusion pressures of 70 and $130 \mathrm{~mm} \mathrm{Hg} .{ }^{10}$

In the presence of a functionally significant coronary stenosis and with a perfusion pressure within the autoregulatory range, coronary flow is maintained because of vasodilatation of the resistive vessels $<100 \mu \mathrm{m}$ diameter, with the magnitude of vasodilatation being inversely proportional to the diameter. ${ }^{11}$ At a perfusion pressure below the autoregulatory range, although the vessels $<100 \mu \mathrm{m}$ dilate maximally, vessels $>100 \mu \mathrm{m}$ decrease in diameter. ${ }^{11}$ Several mechanisms underlying these observations have been proposed. It is likely that vessels $<100 \mu \mathrm{m}$ dilate in response to metabolites released by the myocardium. This effect is suggested not only by their size, but also by their position in relation to the myocardial cells. Vessels $>100 \mu \mathrm{m}$ have a reduced distending pressure probably because the reduction in perfusion pressure causes a passive decrease in vessel diameter: these vessels still vasodilate in response to glyceryl trinitrate and adenosine. A reduction in perfusion pressure has been associated with an increase in $\alpha_{2}$-adrenergic vasoconstriction ${ }^{12}$ or with an alteration in the production of vasodilator metabolites by the myocardium caused by reduced myocardial oxygen consumption, ${ }^{13}$ both of which could cause a decrease in the diameter of vessels $>100 \mu \mathrm{m}$. Sympathetic nerve stimulation or noradrenaline infusion ${ }^{8}$ and serotonin infusion ${ }^{14}$ constrict vessels $>90-100 \mu \mathrm{m}$ while dilating smaller vessels. An increase in myocardial oxygen consumption with pacing causes a generalised vasodilatation in all resistive vessels, which is related inversely to diameter. ${ }^{9}$ This may be because the arterioles $(<100 \mu \mathrm{m})$ are subject to a lower transmural pressure, but they are also probably the only resistive vessels influenced directly by the tissue metabolic state.

As in conduit arteries, an increase in shear stress through increased flow may cause vasodilatation of the microvessels through release of nitric oxide (NO), along with local vasodilators such as adenosine. A longitudinal gradient for flow and metabolically induced 
responsiveness exists within the coronary microcirculation. In one study, ${ }^{15}$ isolated vessels were categorised as small (mean $40 \mu \mathrm{m}$ ), intermediate (mean $60 \mu \mathrm{m}$ ), and large arterioles (mean $106 \mu \mathrm{m}$ ) and small arteries (mean $179 \mu \mathrm{m})$. Increasing shear stress led to a greater increase in vasodilatation as arteriole size increased, but less vasodilatation was seen in the small arteries (similar to small arterioles), suggesting that the large arterioles had the most efficient regulation of this shear stress. ${ }^{15}$ Endothelium-dependent vasodilatation with substance $P$ was seen in all vessels with increasing doses but small arteries achieved only $80 \%$ of the maximal vasodilatation seen in all arteriole groups. In contrast, adenosine preferentially dilated the small arterioles, with progressively increasing molar doses being needed with increasing vessel size. The NO donor, sodium nitroprusside, dilated all vessels equally. ${ }^{15}$

These observations of a variable response in different-sized vessels indicate that the regulation of coronary flow by the resistive vessels is complex and dependent on segmental differences in the response to flow/shear stress and adenosine during physiological stress. Different mechanisms may account for the heterogeneity of the response, such as different populations and subtypes of receptors for vasoactive substances ${ }^{14}$ or variable metabolic pathways. ${ }^{16}$

On this basis, the resistive vessels have been separated into two general groups (figure). ${ }^{17} 18$ The arteriolar vessels $(<100 \mu \mathrm{m})$ respond to local tissue metabolism and maintain the extracellular environment within optimal biochemical limits for myocardial contractile function. The effect is modulated primarily by tissue oxygen tension. Flow is dependent on inherent arteriolar tone and the perfusion pressure at their origin. Perfusion pressure is determined by the pre-arteriolar vessels $(100-350 \mu \mathrm{m})$ which are influenced by coronary perfusion pressure and flow, by myogenic tone, and by neurogenic influences. ${ }^{18} \mathrm{With}$ an increase in myocardial oxygen demand and arteriolar vasodilatation, a pressure drop occurs across the pre-arteriolar vessels with subsequent flow-mediated vasodilatation thus coordinating the vascular response to physiological stress to meet tissue needs. Washout of
A

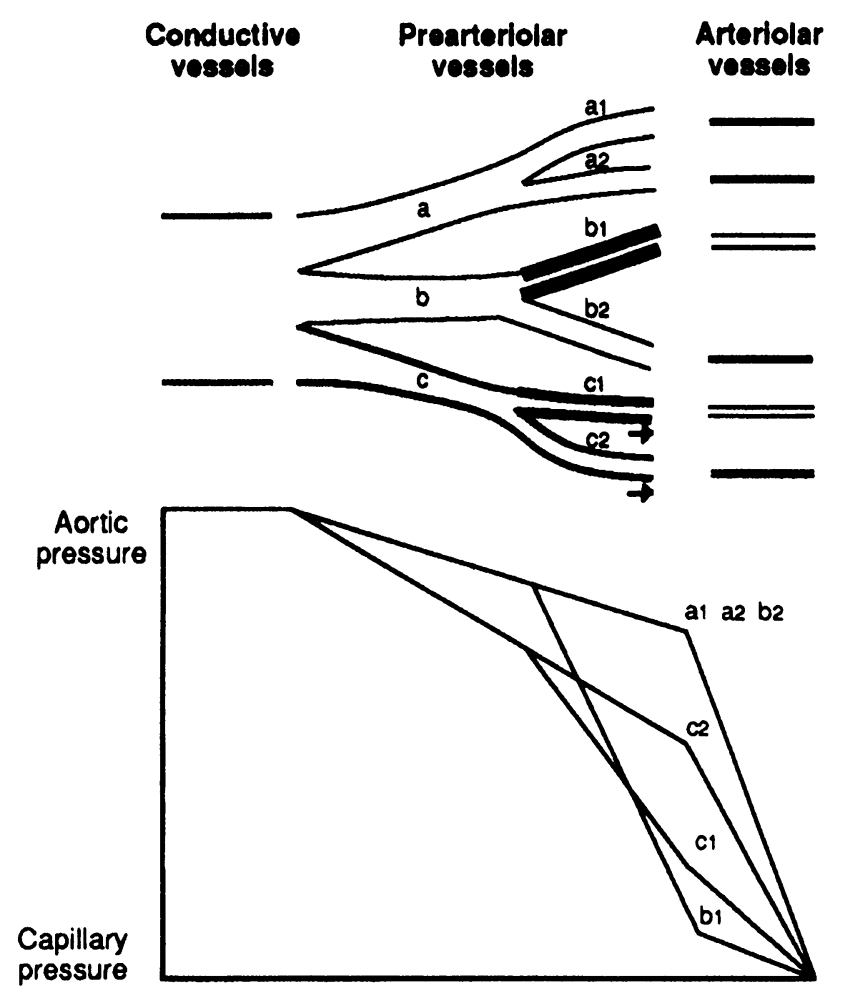

B
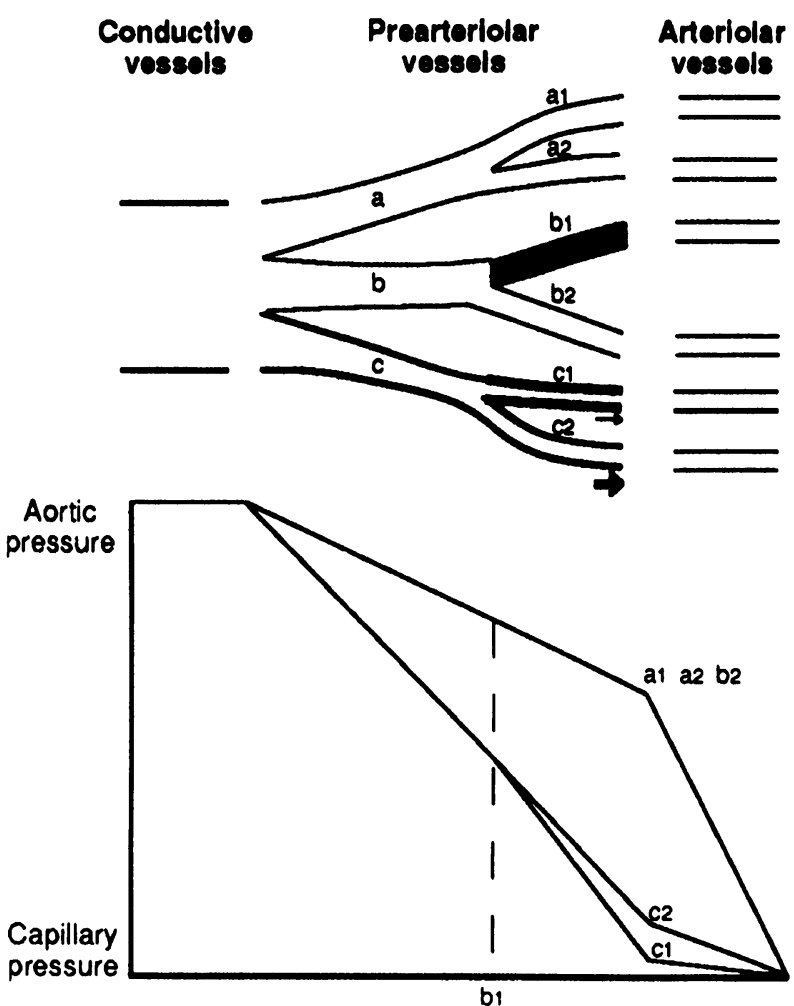

Schematic representation of a conduit coronary artery and prearteriolar and arteriolar vessels with patchily distributed pre-arteriolar constriction in control conditions ( $A$, upper panel) and during arteriolar vasodilatation ( $B$, upper panel). In this functional classification, conduit coronary arteries do not have appreciable flow resistance, arteriolar vessels are responsible for the metabolic autoregulation of coronary blood flow and prearteriolar vessels are those segments interposed between conductive arteriolar vessels with appreciable coronary flow resistance that are responsible for maintaining perfusion pressure at the origin of arterioles within optimal levels. The vasodilatory reserve of arterioles distal to constricted prearteriolar vessels is reduced because they are already dilated to preserve rest flow.

In conduit coronary arteries, the pressure remains similar to aortic pressure, but decreases progressively across prearteriolar vessels in proportion to their degree of constriction ( $A$, lower panel). During metabolic or pharmacological arteriolar vasodilatation, the pressure drop increases only slightly distal to some prearteriolar vessels $\left(a_{1}, a_{2}, b_{2}\right)$ because vasodilatation related to flow-mediated release of endothelium derived relaxing factor compensates nearly completely for the increased flow. The pressure drop increases markedly across more constricted pre-arteriolar vessels $\left(b_{t}, c_{i}, c_{2}\right)(B$, lower panel). Steal can develop when an increase in flow through $c_{2}$ causes a pressure decrease at the branching point distal to the constricted segment $c$, so that the driving pressure becomes insufficient to perfuse adequately the most constricted branch $c_{1}$ and blood flow (as indicated by arrows) can become lower than during rest conditions. The possibility of flow steal is greatly enhanced if branch $c_{2}$ perfuses subepicardial layers of the ventricular wall with a greater flow reserve and if branch $c_{1}$ perfuses the subendocardial layers with a smaller flow reserve. At the end of the pre-arteriolar vessels with the most marked increase in tone ( $b_{1}$ ), intravascular pressure may become insufficient to maintain lumen patency, resulting in vessel collapse. (Reprinted with permission from the American College of Cardiology (fournal of the American College of Cardiology, 1991;17:499-506).) 
metabolites leads to a relative vasoconstriction of arterioles, increasing the pressure head in the pre-arterioles which, through a greater myogenic responsiveness counteracting even flow-mediated vasodilatation, ${ }^{19}$ would limit this increase. With increasing aortic pressure, arteriolar pressure may be maintained by prearteriolar constriction through increased myogenic tone. A marked decrease in aortic pressure leads to dilatation of all resistive vessels. ${ }^{9}$ Vasoconstriction or a failure of pre-arteriolar vessels to dilate would lead to a reduction in flow in the arteriolar bed despite maximal dilatation in response to tissue metabolism.

\section{The regulation of coronary blood flow}

There are two main regulatory mechanisms for the control of flow in the microcirculation-the endothelium and the autonomic nervous system. Endothelial cells produce and release both vasodilator and vasoconstrictor factors with predominant vasodilatation. The major factor modulating vasodilatation is $\mathrm{NO},{ }^{20}$ produced from L-arginine by NO synthetase. ${ }^{21} \mathrm{NO}$ may be released in response to a variety of different stimuli; flow (shear stress), platelet-derived products (ADP, thrombin, serotonin), and vasoactive agents (bradykinin, histamine, noradrenaline, substance $P$, vasopressin). In pathological states vasoconstrictor substances such as endothelin, may override the normal vasomotor tone associated with endothelium-dependent vasodilatation..$^{22}$

In the human coronary circulation, infusion of an inhibitor of NO production caused a small reduction in blood flow in normal arteries, ${ }^{23}$ indicating that a basal release of NO is needed to maintain resting flow. Studies in the peripheral circulation in an animal model showed that NO activity was greatest in vessels $>100 \mu \mathrm{m},{ }^{24}$ which are under the most shear stress, the major determinant of NO release. In an open-chest dog model, inhibition of NO synthesis resulted in constriction of vessels $>100 \mu \mathrm{m}$ and dilatation of arterioles $<100 \mu \mathrm{m}$, but with no overall effect on coronary flow velocity. ${ }^{25}$ Of note, arteriolar vasodilatation and thus the flow response to both adenosine and atrial pacing was abolished by inhibition of NO synthesis. Pre-arterioles dilated less in response to pacing, and dilatation was abolished by NO inhibition whereas arterioles dilated to a greater extent than small arteries in response to papaverine which was unaffected by NO inhibition. A complementary in vitro study indicated, however, that adenosine-mediated dilatation of arterioles was not mediated by NO. ${ }^{25}$ This study confirmed the importance of NO in modulating microvascular flow by dilating the pre-arterioles between $100-300 \mu \mathrm{m}$ thus preserving the vasodilator potential of the arterioles $<100 \mu \mathrm{m} .{ }^{25}$ In atherosclerosis, a loss of this endotheliumdependent mechanism for microcirculatory regulation could account for changes in vasomotor tone at the pre-arteriolar level, upstream from the potent metabolic vasodilator stimuli of hydrogen ions and low tissue oxygen tension.
The autonomic nervous system acts to modulate coronary blood flow through a direct effect on coronary arteries (there are sympathetic neural afferents to vessels $>100 \mu \mathrm{m}$ ) and by catecholamine release. ${ }^{8}$ It has been demonstrated previously that selective $\alpha_{2}$ adrenergic activation may induce endothelialdependent vasodilatation in isolated canine epicardial arteries. ${ }^{26}$ In the open-chest dog model, $\alpha_{1}$ and $\alpha_{2}$ adrenergic activation constricted pre-arterioles and arterioles, respectively. Inhibition of NO synthesis unmasked additional vasoconstriction by $\alpha_{1}$-adrenergic activation in arterioles and $\alpha_{2}$-adrenergic activation in the pre-arterioles. ${ }^{27}$ This implied that NO release, induced by the shear stress of increased coronary flow, opposed $\alpha$-adrenergic vasoconstriction thus limiting the potential reduction in myocardial perfusion during augmented sympatho-adrenal drive. In pathological states, endothelial dysfunction may lead to unopposed $\alpha$-adrenergic vasoconstriction and subsequent pre-arteriolar resistive vessel dysfunction.

\section{Resistive vessel dysfunction in coronary artery disease}

Myocardial ischaemia in the presence of a severe coronary stenosis occurs when perfusion pressure at the origin of maximally dilated arteriolar vessels is so low that there is insufficient blood flow to meet the metabolic requirements of the myocardium. Indeed, if the perfusion pressure is sufficiently low at the origin of the arterioles, it is possible that arteriolar collapse may occur because the intraluminal distending pressure may be insufficient to oppose extravascular pressure. Since myocardial oxygen extraction is already near maximal at rest, and maximal arteriolar dilatation is present, there are no other means to compensate for the reduced flow other than an increase in perfusion pressure. Pharmacological studies have shown that the vasoactive peptides, neuropeptide $\mathrm{Y}$ and endothelin, cause myocardial ischaemia in humans ${ }^{28}$ and conscious $\operatorname{dogs}^{29}$ respectively, with no demonstrable effect on epicardial arteries. In patients with coronary artery disease, myocardial ischaemia may develop due to resistive vessel constriction induced by serotonin, ${ }^{30}$ and this may be exacerbated by the vasoconstrictor action of serotonin on the intramural penetrating arteries (mean diameter $200 \mu \mathrm{m}$ ). ${ }^{31}$ After emergency angioplasty, ischaemia may occur through microvascular constriction, ${ }^{4}$ and this vasoconstriction may be seen in visible distal vessels after an elective procedure. ${ }^{32}$ In patients with chronic angina, inappropriate resistive vessel constriction may contribute to causing myocardial ischaemia. ${ }^{5}$

In a recent study of the microcirculation in normal and atherosclerotic monkeys, serotonin (an endothelium-dependent vasodilator) decreased coronary resistance in normal animals but increased large artery and microvascular resistance in atherosclerotic animals. ${ }^{33}$ Given that the response to adenosine was no different in the two groups, atherosclerosis did 
not impair the vascular smooth muscle response, but was associated with endothelial dysfunction. In another study, isolated cannulated coronary arterioles $(30-70 \mu \mathrm{m})$ from atherosclerotic and normal pigs were studied using the endothelial-dependent agents, ADP, serotonin, and histamine. ${ }^{34}$ These agents induced vasodilatation in only $20-30 \%$ of controls. The response to flow was abolished in denuded normal arterioles and in those from atherosclerotic animals. However, administration of large doses of L-arginine restored normal vasodilator responses to all stimuli. In hypercholesterolaemic animals, the availability of $\mathrm{L}$-arginine can be a rate-limiting factor in endothelial-dependent vasorelaxation in response to receptor-mediated agonists such as acetylcholine. ${ }^{35}$ When $\mathrm{D}$-arginine was used as a control, the oxidised low density lipoprotein (LDL)-cholesterol interfered with receptor-mediated release of L-arginine from intracellular stores or its synthesis in endothelial cells. ${ }^{36}$ Thus it may be that altered resistive vessel responsiveness developing with large vessel disease involves an impairment of the synthesis/release of NO. ${ }^{34}$

In humans, normal epicardial vessels dilate in response to increasing flow through resistive vessel dilatation caused by intracoronary papaverine, but this response is reduced in atherosclerotic arteries. ${ }^{37}$ When three different endothelium-mediated stimuli-acetylcholine, cold pressor stress, and increasing blood flow-were used there was progressive impairment of epicardial vasodilatation with vasoconstriction only to acetylcholine in subjects with hypercholesterolaemia alone, with vasoconstriction to both acetylcholine and cold pressor in patients with a normal artery but with disease elsewhere, and abolition of vasodilatation to all three stimuli in patients with angiographic wall irregularities. ${ }^{2}$ In the microcirculation, vasodilatation to acetylcholine was markedly reduced in patients with smooth arteries and hypercholesterolaemia. In an angiographically normal artery in patients with disease elsewhere, there was also a reduced vasodilator response, particularly when LDL-cholesterol was high. However, compared with the control group, flow-dependent vasodilatation was lower only in those with macroscopic disease. ${ }^{2}$

In patients with hypercholesterolaemia and minimal wall irregularities, intracoronary Larginine infusion before acetylcholine can restore the vasodilator response to that in controls. ${ }^{3}$ In both groups the papaverine response was unimpaired and basal coronary flow was unaffected by an L-arginine infusion, implying that it was during vasodilatation that the deficit in NO production was most prominent. ${ }^{3}$ Thus there is progressive impairment of endothelium-dependent vasodilatation in patients at different stages of the atherosclerotic process.

The assessment of resistive vessel function in clinical studies is dependent on measuring changes in coronary or myocardial blood flow. In patients with comparable coronary stenoses, resistive vessel dysfunction is only one variable along with loading conditions, intramyocardial wall tension, and collaterals in determining absolute myocardial flow. ${ }^{38}$ Nonetheless, there are several clinical models in coronary disease which suggest the presence of resistive vessel dysfunction. After successful angioplasty, the coronary flow reserve may be unchanged from pre-angioplasty values in a significant number of patients, ${ }^{39}$ and impaired for up to 24 hours, ${ }^{40}$ perhaps owing to a combination of platelet activation, vasoconstrictor release, and debris embolisation. Basal flow recovers over several days, suggesting a chronic adaptation pre-angioplasty to the reduction in coronary perfusion pressure. In the absence of restenosis, the recovery of resistive vessel function is sustained after three months with a coronary vasodilator reserve similar to remote regions in patients with stable disease. ${ }^{40}$ However, the mechanisms underlying the impaired vasodilator response early after angioplasty remain uncertain, although in some patients it may reflect suboptimal epicardial dilatation.

There is clinical evidence that resistive vessel dysfunction is present before angiographic disease. ${ }^{41}{ }^{42}$ Using positron emission tomography, in patients with single vessel disease, the coronary flow reserve, although higher than that in stenosis-related regions, was lower than that in the controls, due both to a reduction in the vasodilator response as well as a higher basal flow. ${ }^{41}$ In remote myocardium early after infarction, there is a marked impairment of the vasodilator response which only partially recovers at follow up ${ }^{43}$; this is perhaps evidence for acute resistive vessel dysfunction remote from the infarct region. Although the response to myocardial infarction involves an increase in $\alpha$-adrenergic sympathetic activity which could impair vasodilator responsiveness acutely, vasoconstrictor agents such as endothelin released after injury could also impair the vasodilator reserve. Visible coronary collateral vessels derived from an angiographically normal artery that are sufficient to maintain normal contraction and basal flow are another model of resistive vessel function. An impaired vasodilator response to dipyridamole in collateral-dependent myocardium has been demonstrated with positron emission tomography, ${ }^{44}$ with an inappropriate vasoconstrictor response to cold pressor compared with remote myocardium, ${ }^{45}$ perhaps caused by an increased sensitivity to $\alpha$-adrenergic sympathetic stimulation in the pre-arteriolar vessels.

Atherosclerotic plaque load determines the epicardial artery vasomotor response to endothelium-dependent vasodilatation caused by acetylcholine and to the sympathetic stimulus of cold pressor stress. ${ }^{46}$ This suggests that the extent of intimal thickening and impaired endothelium-mediated vasodilatation are directly related. High serum concentrations of HDL-cholesterol modulate this abnormality by diminishing the degree of vasoconstriction occurring in the diseased segments. In transplant patients at follow up, a vasoconstrictor response to acetylcholine still occurred in 
some patients within the normal range of intimal thickness, indicating that endothelial dysfunction may precede disease detected by intravascular ultrasound. ${ }^{47}$ There is a direct relation between the epicardial and the microcirculatory vasodilator response in these patients, such that the increase in coronary flow with acetylcholine correlates directly with the increase in epicardial coronary diameter. Furthermore, infusion of L-arginine increases the blood flow response to acetylcholine, implying significant reversible endothelial dysfunction in the coronary microcirculation, with the greatest effect of $\mathrm{L}$-arginine in vessels without increased intimal thickening. ${ }^{47}$

The common feature in these studies is the presence of endothelial dysfunction early in the atherosclerotic process and its modulation by L-arginine delivery and oxidised LDL-cholesterol. These observations reinforce the association between endothelial function, cholesterol subfractions, and plaque load in the determination of both the epicardial and microvascular vasodilator responses in humans.

\section{Conclusions}

Resistive vessels may be regarded as two distinct groups: a proximal compartment controlled by flow, distending pressure, and myogenic tone and modulated by the autonomic nervous system and endothelial function; and a distal compartment influenced mainly by the perfusion pressure at the origin of the vessel and by myocardial metabolism. There is already increasing evidence for inappropriate vasomotor tone in the larger resistive vessels in hypertension, ${ }^{48}$ cardiac transplantation, ${ }^{4749}$ and in syndrome X. ${ }^{50}$ It is possible that both the effect of the early atherosclerotic process on endothelial function and alterations in sympathetic drive could also account for such abnormalities in patients with coronary disease. However, the clinical implications of these abnormalities remain uncertain.

1 Chilian WM, Dellsperger KC, Layne SM, Eastham CL Armstrong MA, Marcus ML, Heistad DD. Effects of atherosclerosis on the coronary microcirculation. $A m$ f Physiol 1990;258:H529-H539.

2 Zeiher AM, Drexler H, Wollschläger H, Just $H$. Modulation of coronary vasomotor tone in humans. Progressive endothelial dysfunction with different early Progressive endothelial dysfunction with different early
stages of coronary atherosclerosis. Circulation 1991;83: stages of

3 Drexler H, Zeiher AM, Meinzer K, Just $\mathrm{H}$. Correction of endothelial dysfunction in coronary microcirculation of hypercholesterolaemic patients by L-arginine. Lance 1991;338: 1546-50.

4 Wilson RF, Laxson DD, Lesser JR, White CW. Intense microvascular constriction after angioplasty of acute thrombotic coronary arterial lesions. Lancet 1989;333 807-11.

5 Pupita G, Maseri A, Kaski JC, Galassi AR, Gavrielides S, Davies GJ, Crea F. Myocardial ischemia caused by distal coronary-artery constriction in stable angina pectoris. $N$ Engl ₹ Med 1990;323:514-20.

6 Klocke FJ, Mates RE, Canty JM, Ellis AK. Coronary pressure-flow relationships. Controversial issues and probabure-flow relationships. Controversial iss

7 Chilian WM, Eastham CL, Marcus ML. Microvascular distribution of coronary vascular resistance in beating left distribution of coronary vascular resistance in
ventricle. Am $¥$ Physiol 1986;251:H779-H788.

8 Chilian WM, Layne SM, Eastham CL, Marcus ML Heterogeneous microvascular coronary alpha-adrenergic vasoconstriction. Circ Res 1989;64:376-88.

9 Kanatsuka H, Lamping KG, Eastham CL, Dellsperger KC, Marcus ML. Comparison of the effects of increased myocardial oxygen consumption and adenosine on the coronary microvascular resistance. Circ Res 1989; 65:1296-305

10 Mosher P, Ross J, McFate P, Shaw RF. Control of coronary blood flow by an autoregulatory mechanism. Circ Res 1964;14:250-8.

11 Kanatsuka H, Lamping KG, Eastham CL, Marcus ML. Heterogeneous changes in epimyocardial microvascular size during graded coronary stenosis. Evidence of the microvascular site for autoregulation. Circ Res 1989; 66:389-96.

12 Heusch G, Duessen A. The effects of cardiac sympathetic nerve stimulation on perfusion of stenotic coronary arteries in the dog. Circ Res 1983;53:8-15.

13 Aversano T, Becker LC. Persistence of coronary vasodilator reserve despite functionally significant flow reduction. Am f Physiol 1985;248:H403-H411.

14 Lamping KG, Kanatsuka H, Eastham CL, Chilian WM Marcus ML. Nonuniform vasomotor responses of the coronary microcirculation to serotonin and vasopressin. Coronary microcirculation

15 Kuo L, Davis MJ, Chilian WM. Longitudinal gradients for endothelium- dependent and -independent vascular responses in the coronary microcirculation. Circulation 1995;92:518-25.

16 Kurz MA, Lamping KG, Bates JN, Eastham CL, Marcus ML, Harrison DG. Mechanisms responsible for the heterogeneous coronary microvascular response to nitroglycerin. Circ Res 1991;68:847-55.

17 Epstein SE, Cannon RO III. Site of increased resistance to coronary flow in patients with angina pectoris and norma epicardial coronary arteries. $\mathcal{F} \mathrm{Am}$ Coll Cardiol 1986; 8:459-61.

18 Maseri A, Crea F, Kaski JC, Crake T. Mechanisms of angina pectoris in syndrome X. $7 \mathrm{Am}$ Coll Cardiol 1991;17:499-506

19 Kuo L, Chilian WM, Davis MJ. Interaction of pressureand flow-induced responses in porcine coronary resistance vessels. Am F Physiol 1991;261:H1706-H1715.

20 Palmer RMJ, Ferrige AG, Moncada S. Nitric oxide release accounts for the biological activity of endotheliumderived relaxing factor. Nature 1987;327:524-526.

21 Palmer RMJ, Ashton DS, Moncada S. Vascular endothelial cells synthesize nitric oxide from L-arginine. Nature 1988;333:664-6.

22 Yanagisawa $M$, Kurihara $H$, Kimura $S$, Tomobe $Y$, Koyabashi M, Mitsui Y, Yazaki Y, Goto K, Masaki T. A novel potent vasoconstrictor peptide produced by vascular endothelial cells. Nature 1988;322:411-5.

23 Lefroy DC, Crake T, Uren NG, Davies GJ, Maseri A Effect of inhibition of nitric oxide synthesis on epicardial coronary artery caliber and coronary blood flow in coronary artery caliber and coron

24 Griffith TM, Edwards DH, Davies RL, Harrison TJ, Evan $\mathrm{KT}$. EDRF coordinates the behaviour of vascular resistance vessels. Nature 1987;329:442-5.

25 Jones CJH, Kuo L, Davis MJ, DeFily DV, Chilian WM. Role of nitric oxide in the coronary microvascula responses to adenosine and increased metabolic demand. Circulation 1995;91:1807-13.

26 Cocks TM, Angus JA. Endothelium-dependent relaxation of coronary arteries by noradrenaline and serotonin. Nature 1983;305:627-9.

27 Jones CJH, DeFily DV, Patterson $\pi$ Chilian WM Endothelium-dependent relaxation competes with alpha1- and alpha-2-adrenergic constriction in the canine epi-
cardial coronary microcirculation. Circulation 1993; cardial corona

28 Clarke JG, Davies GJ, Kerwin R, Hackett D, Larkin S, Dawbarn D, Lee Y, Bloom SR, Yacoub M, Maseri A. Coronary artery infusion of neuropeptide $\mathrm{Y}$ in patients with angina pectoris. Lancet 1987;330:1057-9.

29 Larkin SW, Clarke JG, Keogh BE, Araujo LI, Rhodes CG Davies GJ, Taylor KM, Maseri A. Intracoronar endothelin induces myocardial ischemia by small vessel constriction in the dog. Am $\mathcal{F}$ Cardiol 1989;64: 956-8.

30 McFadden EP, Clarke JG, Davies GJ, Kaski JC, Haider AW, Maseri A. Effect of intracoronary serotonin on coronary vessels in patients with stable angina and patients with variant angina. $N$ Engl F Med 1991;324:648-54.

31 Bache RJ, Stark RP, Duncker DJ. Serotonin selectively aggravates subendocardial ischemia distal to a coronary artery sten.

32 Fischell TA, Bausback KN, McDonald TV. Evidence for altered epicardial coronary artery autoregulation as a cause of distal coronary vasoconstriction after successful percutaneous transluminal coronary angioplasty. $\mathcal{F}$ Clin Invest 1990;86:575-84.

33 Chilian WM, Dellsperger KC, Layne SM, Eastham CL, Armstrong MA, Marcus ML, Heistad DD. Effects of
atherosclerosis on the coronary microcirculation. $A m \mathcal{F}$ Physiol 1990;258:H529-H539.

34 Kuo L, Davis MJ, Cannon S, Chilian WM. Pathophysiological consequences of atherosclerosis extend into the coronary microcirculation. Restoration of endothelium-dependent responses by L-arginine. Circ Res 1992;70:465-76

35 Cooke JP, Andon NA, Girerd XJ, Hirsch AT, Creager MA. Arginine restores cholinergic relaxation of hypercholesArginine restores cholinergic relaxation of hypercholes-
terolemic rabbit thoracic aorta. Circulation 1991;83: terolemic

36 Tanner FC, Noll G, Boulanger CM, Lüscher TF. Oxidized low density lipoproteins inhibit relaxations of porcine 
coronary arteries: role of scavenger receptor and endothelium-derived nitric oxide. Circulation 1991;83: 2012-20.

37 Drexler H, Zeiher AM, Wollschläger H, Meinertz T, Just $\mathrm{H}$, Bonzel T. Flow-dependent coronary artery dilatation in humans. Circulation 1989;80:466-74.

38 Uren NG, Melin JA, De Bruyne B, Wijns W, Baudhuin T, Camici PG. Relation between myocardial blood flow and severity of coronary-artery stenosis. $N \mathrm{Engl} f \mathrm{Med}$ 1994;330:1782-7.

39 Wilson RF, Johnson MR, Marcus ML, Aylward PEG, Skorton DJ, Collins S, White CW. The effect of coronary Skorton DJ, Collins S, White CW. The effect of coronary angioplasty

40 Uren NG, Crake T, Lefroy DC, de Silva R, Davies GJ, Maseri A. Delayed recovery of coronary resistive vesse function after coronary angioplasty. $\mathcal{F} \mathrm{Am} \mathrm{Coll} \mathrm{Cardio}$ 1993;21:612-21.

41 Uren NG, Marraccini P, Gistri R, de Silva R, Camici PG Altered coronary reserve and metabolism in norma myocardium of patients with coronary artery disease. $\mathcal{f}$ Am Coll Cardiol 1993;22:650-8.

42 Sambuceti G, Parodi O, Marcassa C, Neglia D, Salvadori PA, Giorgetti A, Bellina $R$, Di Sacco $S$, Nista $N$, Marzullo $P$, Testa $R$, 'Abate A Alteration in regulation of myocardial blood flow in one vessel coronary tion of myocardial blood flow in one vessel coronary phy. Am ₹ Cardiol 1993;72:538-43.

43 phy. Am $f$ Cardiol $193,72.538-43$.

Maseri A Reduced Maseri A. Reduced coronary vasodilator function in infarction. N Engl F Med 1994;331:222-7.
44 McFalls EO, Araujo LI, Lammertsma AA, Rhodes CG, Bloomfield P, Pupita G, Jones T, Maseri A. Vasodilator reserve in collateral-dependent myocardium as measured by positron emission tomography. Eur Heart $\mathcal{f} 1993$; 14:336-43.

45 Uren NG, Crake T, Tousoulis D, Haider AW, Seydoux C, Lefroy DC, Davies GJ, Maseri A. Impairment of the myocardial blood flow response to cold pressor in collateral-dependent myocardium (abstract). Circulation 1992;84:I-853.

46 Zeiher AM, Schächinger V, Hohnloser SH, Saurbier B, Just $\mathrm{H}$. Coronary atherosclerotic wall thickening and vascular reactivity in humans: elevated high-density lipoprotein levels ameliorate abnormal vasoconstriction in early therosclerosis. Circulation 1994;89:2525-32.

47 Drexler H, Fischell TA, Pinto FJ, Chenzbraun A, Botas J, Cooke J, Alderman EL. Effect of L-arginine on coronary endothelial function in cardiac transplant recipients: relation to vessel wall morphology. Circulation 1994;89: 1615-23.

48 Brush JE, Cannon RO, Schenke WH, Bonow RO, Leon MB, Maron BJ, Epstein SE. Angina due to coronary microvascular disease in hypertensive patients without left ventricular hypertrophy. $N$ Engl $f$ Med 1988;319: 1302-7.

49 Treasure CB, Vita JA, Ganz P, Ryan TJ Jr, Schoen FJ, Vekshtein VI, et al. Loss of the coronary microvascular response to acetylcholine in cardiac transplant patients. response to acetylcholine in

50 Cannon RO, Watson RM, Rosing DR, Epstein SE. Angina caused by reduced vasodilator reserve of the small coronary arteries. $\mathcal{F}$ Am Coll Cardiol 1983;1:1359-73. 